\title{
The concentration, flux and occurrence process of total phosphorus in Dahuofang reservoir and Suggestions for environmental optimal operation
}

\author{
Xinghua $\mathrm{Li}^{1,2}$, Dan Dai ${ }^{2,3}$, Xiangqin $\mathrm{Xu}^{2}$, Guoxian Huang ${ }^{2,4^{*}}$, Mingdong Sun ${ }^{2}$,Tong wang ${ }^{5}$, Honggang Yuan ${ }^{6}$ \\ ${ }^{1}$ Chongqing Jiaotong University, Chongqing 400074, China \\ ${ }^{2}$ Chinese Research Academy of Environmental Sciences, Beijing 100000, China \\ ${ }^{3}$ College of Water sciences, Beijing Normal University, Beijing 100875, China \\ ${ }^{4}$ State Key Laboratory of Plateau Ecology and Agriculture, Qinghai University, Xining, 810016, China \\ ${ }^{5}$ Liaoning Academy of Environmental Sciences, Shenyang, 110161, China \\ ${ }^{6}$ Liaoning YingRui Environmental Technology Engineering Co., Ltd., Fushun, 113006, China
}

\begin{abstract}
Dahuofang reservoir is one of the most important drinking water sources in Liaoning province, China. Dynamics of total phosphorus (TP) concentration, flux and related retention processes in this reservoir are very important to the water quality management and drinking water safety. Based on the monitoring data of meteorology, hydrology, water quality and sediment from the main stations during 1992-2017, this paper analysed the TP fluxes in the different boundaries and the stocking process in both the overlying water and the active surface sediment layer using the mass balance method. This study revealed the TP accumulation variation in the overlying water and the surface sediment layer and the controlling mechanism of TP concentration in overlying water under different hydrological conditions. The results showed that the combination of flood and dry hydrological rhythms is important to maintain the dynamic balance of TP in the reservoir. Based on these results, to reduce the TP retention rate and accumulated TP in the active surface sediment layer, we put forward suggestions on environmental optimization operations during the early days of large flood and subsequent small flood season by opening the deep flood discharging holes of the reservoir and lowering upstream water level. These results provide an improved understanding and new eyesight of the nutrient control of large reservoirs in the north China.
\end{abstract}

\section{INTRODUCTION}

Effective controlling the input of nitrogen and phosphorus is an effective way to ensure water supply safety and reduce the risk of eutrophication in the river - lake estuary system ${ }^{[1]}$. However, even though the external loadings have been controlled, much of nitrogen and phosphorus may still be stocked in the sediment layer due to the long-term effects of previous high input loads and subsequent sedimentation. The pollutant concentration level is still in a relatively high level due to endogenous release $^{[2,3]}$, which may cause the imbalance of nitrogen and phosphorus ratio and algae bloom ${ }^{[4]}$.

Dahuofang reservoir is one of the most important drinking water sources in Liaoning province, China. It is a key source of drinking water for seven cities in Liaoning province including Fushun, Shenyang, and Dalian, et al. The population of the water supply area is more than 23 million. Total nitrogen (TN) concentration always exceeds class II standard, while total phosphorus (TP) is occasionally exceeds in this reservoir, referring to the national water quality standard for surface flow (GB3838-
2002). The concentration level and changing process of the TN and TP are crucial to the eutrophication state and water safety. In general, phosphorus is the most critical limiting factor for freshwater eutrophication and algae blooms ${ }^{[5]}$. Therefore, it is important to quantitative analyse the phosphorus concentration, the flux and its occurrence process in the reservoir.

Currently, the quantitive analysis on the variation trend, budget of related flux, accumulated stocking in the sediment layer become one of hot issues worldwide. The input phosphorus may have a tightrelation with the upstream input, atmospheric deposition, and endogenous release, together with the point and none point sources from the numerous local small catchments without control stations. The output of phosphorus are mainly decided on flow discharge, biological assimilation, sedimentation, and so on. Due to phosphorus transport (especially particulate phosphorus) has a close relationship with the watershed flood process, pollution source, and the sediment movement in the upper cathoments and streams [6]. Meanwhile, the TP composition, concentration and flux during the flood period have a highly variability and the related budget results may have an large uncertainty

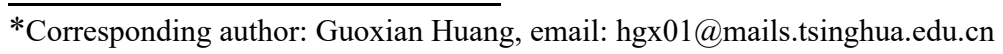


and error ${ }^{[7-9]}$ (Johnes 2007, O'Brien et al. 2016). Viviano et al. (2014) results showed that the low frequency measurement would cause the underestimation of TP point source and reduction the measuring load by $34 \%$. Therefore, the monitoring frequency of sediment and TP during the flood period need to be significantly increased. Moreover, the observation of TP components on the different suspended sediment particles in the turbidity water sample also needs to be supplemented ${ }^{[10,}{ }^{11]}$. Compared with Europe, the enough observation of phosphorus deposition in China is still shortage ${ }^{[12]}$. The limited observation showed that TP deposition in the forest area of Dahuofang reservoir is ranged from 0.41 to $0.8 \mathrm{~kg} . \mathrm{Ha}-1 . \mathrm{a}-1^{[13]}$ (Du et al. 2016), while the monitoring data related to TP deposition process at different weather conditions are shortage in this reservoir. In addition, the phosphorus process linked to biological activities in the reservoir are relatively complex and it is difficult to give a quantitative evaluation for thegrowth, reproduction, migration, grazing, excretion, death and disturbance of aquatic plants, algae, microorganisms and animals. The direct effects of retention, migration, absorption, transformation, deposition, and release of $\mathrm{P}$ or through changing DO and $\mathrm{PH}$ to promote or inhibit the release of phosphorus, etc ${ }^{[14]}$.

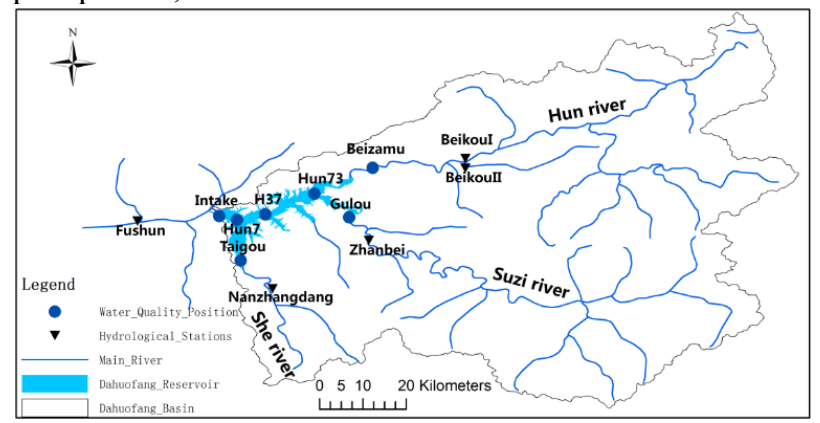

Figure 1. The map of Dahuofang river basin and reservoir

Phosphorus has been paid great attention wordwidely in terms of transformation mechanism, concentration variation, flux budget, retention, sediment occurrence and and optimal controllprocess for different catchments and water regions. This manuscript uses a long-term monitoring data of TP from 1992-2017, firstly the longterm changing trends of annual averaged TP concentration were analysed at the three input control stations and reservoir area with total 5 monitoring stations, and then the dynamic changes of phosphorus flux and occurrence process in the overlying water and active sediment layer of the reservoir during 2008-2017, and the special effects driven by the flood hydrological conditions in 2010 and 2013 to the import and export total phosphorus flux, sedimentation, release and occurrence. The research has a positive significance for the scientific understanding of TP process and the environment optimization managment for the reservoirs in North China.

\section{MATERIALS AND METHODS}

The daily measured data of the water level, flow discharge and suspended concentration at the 5 controlled station during 1990-2017 was collected from the management of Dahuofang Reservoir and the Hydrology Bureau of
Liaoning Province. Water quality data was collected from Fushun Academy of Environmental Sciences. The analysis methods of the water quality were given in the literature $^{[15]}$, the annual averaged TP concentration was solved by monthly measured data. For the consistent calculation of TP flux, the unequal interval temporal interpolation method was used to interpolatemonthly measured data into daily data based on the Akima method [16]. Considering the relative higher monitoring frequency of water quality compared to the data from 1992-2007, the measured data from 2008 to 2017 were used to analyse the flux and occurrence process. The topographic data of the reservoir is mainly based on the survey data in 2005, and the additional elevation data named Strim V3.1 $90 \mathrm{~m}$ has also been used in water - land transition region. The different data are united using Gauss Kruger 3 Degree Projection and $\mathrm{Xi}$ 'an 80 Coordinate System and then merged together. The irregular triangle network (TIN) of these discrete points in Dahuofang Reservoir was generated by combining the boundaries of the reservoir area. The reservoir elevation-area and volume curves were calculated based on the TIN. The calculated curves based on the TIN is in good agreement with the related curves used in actual operation of the reservoir, which indicated that the terrain data and related process methods used in this paper are reliable.

Due to the lack of detailed measured data such as sediment thickness, gradation, phosphorus concentration and active mud layer thickness in the reservoir area, the existed sediments data in the middle area ${ }^{[17]}$ were used to represent the sediment characteristics in the whole reservoir. The composition of sediment in the $0-41 \mathrm{~cm}$ layer is mainly clay and silt, which varies in the vertical direction. The average proportion of clay, silt and sand in the $0-35 \mathrm{~cm}$ silt layer is $34.23 \%, 63.35 \%$ and $2.44 \%$, respectively. The averaged particle size is $5.0-12 \mu \mathrm{m}$. The thickness of the silt in the reservoir is $0.3-0.6 \mathrm{~m}^{[18]}$. Phosphorus concentration in bed sediment of the lower reach of input river channels, fluctuating backwater area and reservoir area were $1440 \mathrm{mg} / \mathrm{kg}, 529 \mathrm{mg} / \mathrm{kg}$ and 800 $\mathrm{mg} / \mathrm{kg}$ respectively based on the literatures ${ }^{[19-21]}$. The interaction of the phosphorus between the sediment and the overlying water is very complicated, mainly related to the following factors: 1) the thickness of the effective active layer, 2) the characteristics of sediment particles, 3) the pore water content, , the $\mathrm{pH}$ value and the dissolved oxygen level, 4) the phosphorus concentration in the active layer, 5) the biological activities and 6) the hydrodynamic characteristics of the overlying water, etc. Considering the main part of the reservoir is more than 20 $\mathrm{m}$ in depth, the bed sediment particles are less likely to be strongly disturbed, we concluded that the effective adsorption-release active layer thickness for TP is $1-2 \mathrm{~cm}$. Combined with the TP concentration in the surface layer, we evaluated that the volume of the effective adsorptionrelease sediment layer was $1.18 \times 106 \mathrm{~m} 3$ and theTP weight $\mathrm{TP}$ in the active surface sediment layer of the reservoir was $1820 \mathrm{t}$.

Using the daily temporal scale, the mass equilibrium equation of TP in the reservoir was established and shown in $(1-a)$ : 


$$
\begin{gathered}
\sum_{1}^{N I} Q_{\text {In }}(k) \cdot C_{\text {In }}(k) \cdot \text { Tsec }_{\text {Day }}+ \\
\sum_{1}^{N O} Q_{\text {Out }}(k) \cdot C_{\text {Out }}(k) \cdot \text { Tsec }_{\text {Day }}+ \\
P=W s+\text { Wbio } \\
P=P d r y+P w
\end{gathered}
$$

Where $Q_{I n}(k)$ and $C_{I n}(k)$ are the daily average flow discharge $\left(\mathrm{m}^{3} / \mathrm{s}\right)$ and daily average TP concentration $(\mathrm{kg} / \mathrm{m} 3)$ of the kth inflow river respectively. $Q_{\text {Out }}(k)$ and $C_{\text {Out }}(k)$ are the average daily flow and TP concentration for the kth outflow river respectively,Tese $e_{\text {Day }}$ is the included seconds for a day, $\mathrm{P}$ is the daily TP deposition weight $(\mathrm{kg} / \mathrm{d}), W S$ is the sum of the TP weight in overlying water and in the effective exchange sediment layer, which is equal to the sum of Wwat and Wsed. The overlying water TP weight was solved by partition zone method according to the closest distance rule. in every sub-zone, there is a water quality monitoring station existed, the averaged water quality in the sub-zone is represented by the measured value at the station. By this way, the water volume and the overlying water TP quality in each sub-zone were solved based on the elevation at triangle cells of the sub-zone and the daily variation of the water level in at the dam site. Finally, the cumulative process of TP weight in overlying water was solved. This method considered effectively the difference of the spatial and temporal TP distribution, and reduced the solution error. The formula for solving the TP weight in the overlying water at the moment of $\mathrm{n}$ time is: $W w a t^{n}=\sum_{N r=1}^{N r e g}\left(C_{N r}^{n} \cdot V_{N r}^{n}\right)$. Where, Nreg is the number of sub-zones of the reservoir, and its value is equal to the number of control stations in the river channel and the reservoir area. $C_{N r}^{n}$ is the TP concentration in each sub-area at time $\mathrm{n}$, the unit is: $\mathrm{kg} / \mathrm{m} 3, V_{N r}^{n}$ is the water volume of each sub-area at time $\mathrm{n}$. The result is mainly determined by the water level in front of the dam and the topographic distribution of each sub-area. The dynamic process of TP occurrence in the sediment layer of the reservoir was mainly determined by the formula 1-a, and c. At the beginning of the calculation, the TP in the active sediment layer was $1820 \mathrm{t}$. Based on the TP concentration in overlying water, and the input and output formula for TP flux, the TP weight in the surface layer of the active sediment can be calculated.

\section{THE TP VARIATION OF DAHUOFANG RESERVOIR}

\subsection{The annual variation of TP after 1992}

The seasonal data during 1992-2002 and monthly data during 2003-2017 were averaged according to annual scale. The result was shown in Figure 2. the variation characteristics of the annual concentration of TP in the three main inflow rivers and the reservoir were analyzed and listed as follows: 1) the annual fluctuation of TP concentration in the Dahuofang catchment is relatively large, with the maximum fluctuation of $0.118,0.084$, 0.079 and $0.102 \mathrm{mg} / \mathrm{l}$ in Beizamu, Gulou, Taigou and the reservoir respectively. The trends of long-term concentration level of TP in the three major inflow rivers and the reservoir were not significant increasing or reducing. The TP concentration in the Beizamu declined from 1992 to 2003 and then increased from 2004 to 2017. While in Suzi River, it generally increased from 1992 to 2004 and decreased from 2005 to 2017. The TP at Taigou from 2006 to 2017 showed a decreasing trend. During the period from 1992 to 2017 , the TP concentration in the reservoir showed a decreasing trend. The increasing of TP concentrations at the three control stations and reservoir area during the flood season are much higher than the other seasons, which indicated that the flood has a significant influence on the TP concentration at the input control stations and reservoir area.

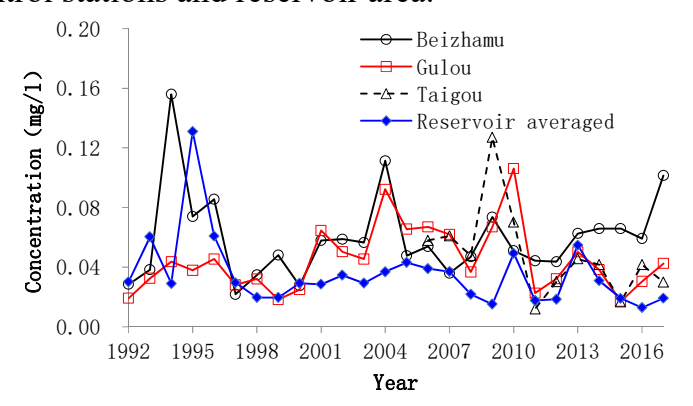

Figure 2 . The annual average TP concentration at the control stations and reservoir area of Dahuofang (1992-2017)

\subsection{Analysis of TP concentration during flood in in 2010 and 2013}

Under the small and medium floods, the reservoir has a sedimentation and purification effects on the input TP associated with suspended sediment from the three main rivers. The corresponding TP concentration level in the reservoir area is relatively lower, which fluctuates in the second-class water quality control line, but during the flood period, the TP concentration has increased remarkably, which has brought difficulties to the utilization of the drinking water resources. In order to further analyse the mechanism for the TP concentration rising during floods, the TP concentration at four control stations in the reservoir area were selected during the flood periods in 2010 and 2013. The estimated concentration of the Hun River and the Suzi River were combined and uniformly mixed using the formula $C_{\text {mix }}=$ $\frac{\left(Q_{H u n} \cdot C_{H u n}+Q_{S h u} \cdot C_{S h u}\right)}{\left(Q_{H u n}+Q_{S h u}\right)}$. The result is shown in Figure 3a, b. In 2010, the high flow discharge and TP concentration mainly came from Suzi river basin, and its maximum TP concentration reached $0.36 \mathrm{mg} / \mathrm{l}$ on August 2nd, 2010, while the TP concentration in the Hun River was relative smaller than the Suzi river, and the concentration at the Beizamu station in same period was only about $0.09 \mathrm{mg} / \mathrm{l}$. The TP concentrations at the sections Hun37 and Hun7 in the reservoir area were slightly lower than those in the upstream of Hun river and it showed the sedimentary TP in the active bed layer of the extension beach along the curved and lotus nodal shape channels in the middle and lower reach of the Hun River was not fully washed off effectively and the TP may be deposited in the backwater area and the middle part of the reservoir. However, the 
concentration of TP increases at the exit of reservoir, and the maximum values increase from 0.19 to $0.23 \mathrm{mg} / \mathrm{l}$. The main reason may be that TP resuspension and release in the front area of dam driven by the reservoir's flood discharge. Although the total amount of water in the basin is relatively large in 2010, the rainfall is relatively uniform, the duration is long and the rainfall intensity is relatively small. At the same time, there is not serious erosion and high sediment laden flow appeared in the industrial and urban areas of the lower reach of the Hun River. Therefore, the TP process in the reservoir area is mainly determined by the upstream input and the suspension contribution in the dam area is relatively small, and the TP concentration in the reservoir area is greater than $0.10 \mathrm{mg} / 1$ for about 3 months. After the flood, the TP concentration in the reservoir area decreases rapidly.

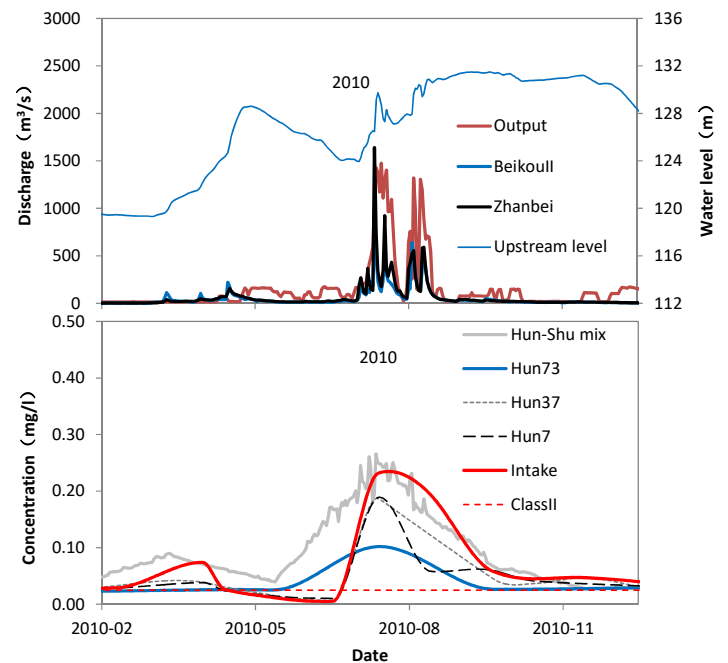

Figure 3. The flow and TP processes in Dahuofang area during the floods in 2010 .

Compared with the floods in Suzi river basin in 2010, the floods in 2013 mainly occurred in the Hun river basin, which had a shorter flood duration lasted for only 12 days and a larger peak discharge with the maximum daily flow discharge of $2830 \mathrm{~m} 3 / \mathrm{s}$ at BeikouII hydrological stations on August 17th, 2013. The instantaneous maximum flow discharge reaches $6720 \mathrm{~m} 3 / \mathrm{s}$, and the related high sediment concentration laden flow appeared with 56.6 $\mathrm{kg} / \mathrm{m} 3$. However, the concentration of TP from the Beizhamu Station in Hun river Province is not high.

The flood in Hun River triggered the high concentration level of TP in the reservoir area in 2013, the main reasons are: 1) under the condition of high sediment concentration laden flow, the TP in the sediment of the reservoir area and the extension beach along the curved and lotus nodal shape channels in the lower reach of the Hun River has strong resuspended during the floods and then releasing in subsequent 2-3 months. From the upper reaches of the reservoir to the dam site, the TP concentrations at the section Hun73, Hun37, No.7 and reservoir outlets have the consistent increasing trends from up reach to lower reach. 2) At the same time, due to the sediment transportation, the slow sedimentation and the resuspension in the reservoir area the turbidity at the Fushun water intake near the dam site is greater than 500 NTU from August 18th to August 25th, 2013. During the period, the maximum value reaches about 1000 NTU, and the turbidity is still around 150 NTU until October 1st of that year[22]. During this period, the suspended sediment concentration in the intake is ranged from 2.7 to $0.5 \mathrm{~kg} / \mathrm{m} 3$. The corresponding TP concentration level in the reservoir area was maintained at more than $0.1 \mathrm{mg} / \mathrm{l}$ in December of that year.

In summary, the floods in Dahuofang basin in 2010 mainly came from the Suzi river, which has the characteristics of large flood volume, long duration, low suspended concentration and gentle flood peaks. The TP concentration in reservoir area has a good consistency with the flood process, and it exceeds the Class II water quality standard and mainly be driven by the upstream input. In 2013, the maximum flood in the basin was from Hun river, which had the characteristics of short duration, large peak discharge and high sediment concentration, and the flood had a long-term effect on TP increasing in the reservoir area. The main reason is that the short-term large and high sediment concentration laden flow has strong scouring capacity and subsequent resuspension effect in Dahuofang area. In addition, the TP releasing from the active surface sediment layer and suspended sediment particles significantly increased the TP concentration in the reservoir area. The high TP concentration level was mainly triggered by short-term large sediment laden floods and subsequent TP releasing.

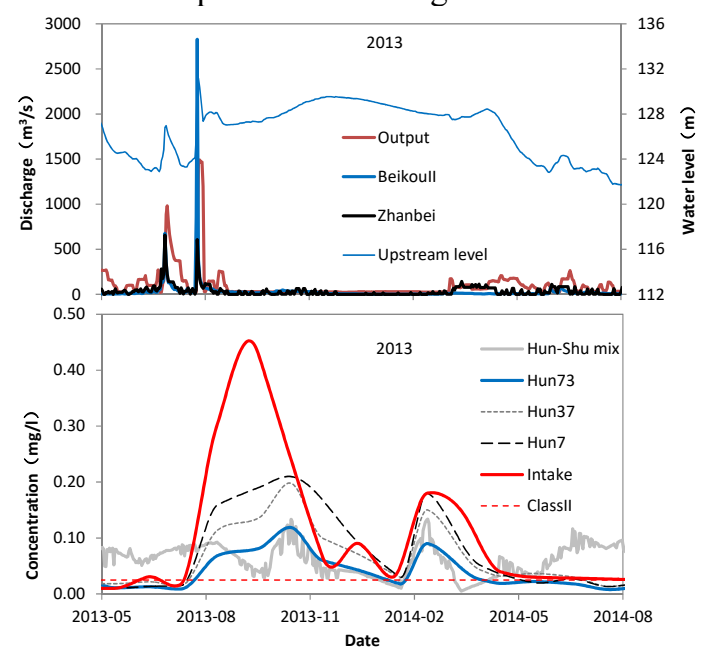

Figure 4. The flow and TP processes in Dahuofang area during the floods in 2013.

\subsection{Analysis of daily TP flux and occurrence dynamics of Dahuofang reservoir}

Based on the formula 1, we calculated the input and output TP flux from the reservoir respectively, and then the changes of the TP weight in overlying water and in the active surface sediment of the reservoir on the daily scale. The daily variation of TP weight in the overlying water and the surface sediment was mainly determined by the daily TP input and output fluxes. The result in Figure 5 showed that: 1). The TP weight in overlying water was mainly controlled by the TP concentration of each station and the water volume of the reservoir. Because of the high TP concentration, the TP weight in the overlying water was higher than $150 \mathrm{t}$ in 2010 and 2013. In the other years during 2008-2017, the TP weight in the overlying water 
was less than $50 \mathrm{t}$ because of low TP concentration under the small or medium floods; 2). Due to the suspension of the sediment driven by the flood and the TP release from the sediment, 150 300 tons of TP was washed off in the bottom sediment, which accounting for a considerable ratio of $8.2 \% \sim 19.2 \%$ of TP weight in the surface sediment layer. The decreased weight of TP in the sediment was closely related to the flood type, the reservoir's operation mode, the early sediment TP accumulative amount, and sensitive environmental factors (e.g. temperature, $\mathrm{pH}$ and DO). Based the results in Figure 5, the TP weight in the active surface sediment has a general rule as "gradually accumulated in the small flood year and rapidly decreased in the large flood year". Considering the TP concentration process in overlying water, the flood increased the reservoir's TP concentration and caused the adverse effects on drinking water quality and safety. However, the flood effectively reduced the TP content in the active surface sediment layer, which may further reduce the risk of the algae blooms. In the early stage of flood, due to the higher TP concentration from the inflow rivers and the relative longer water exchange time in the reservoir, the total weight of TP in the reservoir will increase. Following by the constantly releasing of TP from the surface sediment disturbed by the flood shear stress and flow turbulence, the TP weight in the overlying water will increase rapidly.

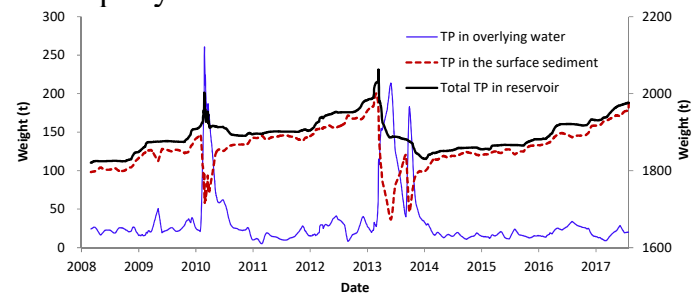

Figure 5. Accumulated TP variations in the overlying water and active surface sediment layer of Dahuofang reservoir (2008-2017).

\section{Suggestions for environmental optimal operations}

In order to keep reasonable $\mathrm{TP}$ concentration in the overlying water and avoid the continuous rising of the accumulated TP weight in the active surface sediment layer in this reservoir, the three key measures should be highlighted: I) the natural hydrological rhythm including large, medium and small floods should be maintained; II) The series of pollutant reduction plans and related clean motions should be supplemented and carried out in the Dahuofang drainage area; III) Environmental optimal operation methods should be designed, tested and evaluated at different hydrological, sediment and pollutant conditions. The suggestions for the environmental optimal operation presented as following:

1) The optimal open modes and time for flood discharge holes and gates should be tested for effectively reduction for the TP weight in the overlying water and the surface sediment layer especially during flood control period;

2) 1-D, 2D and 3D sediment-TP models should be built or applicated to test unsteady transport, the spatial and temoral distribution of phosphorus concentration in the overlying water and sediment layers under the different hydrological conditions, rhythms and reservoir regulation modes (e.g. high sediment laden flows, the different regulated water level and Freezing and thawing process, etc.).

3) Integrated model system including numerical simulation of flow, sediment and TP process in Dahuofang catchment-river-reservoir system are built for different targets, in which the algorithms for the optimal reservoir regulations based on the modern intelligent methods such as genetic algorithm (GA) and Particle Swarm Optimization(PSO), etc.

\section{Reference:}

1. Conley DJ, Likens GE. Ecology. Controlling eutrophication: nitrogen and phosphorus[J]. Science. 2009, 323(5917):1014.

2. Jeppesen E, Søndergaard M, Jensen JP, Havens KE, Anneville O, Carvalho L, et al. Lake responses to reduced nutrient loading - an analysis of contemporary long-term data from 35 case studies[J]. Freshwater Biology. 2010， 50(10):1747-71.

3. Søndergaard M, Jensen JP, Jeppesen E. Role of sediment and internal loading of phosphorus in shallow lakes[J]. Hydrobiologia. 2003, 506-509(13):135-45.

4. Ding S, Chen M, Fan X, Qin B, Xu H et al. Internal phosphorus loading from sediments causes seasonal nitrogen limitation for harmful algal blooms[J]. Sci Total Environ. 2018:872-84.

5. Carpenter SR. Phosphorus control is critical to mitigating eutrophication[J]. Proceedings of the National Academy of Sciences of the United States of America. 2008, 105(32):11039-40.

6. Bowes MJ, Jarvie HP, Halliday SJ, Skeffington RA, Wade AJ, Loewenthal $\mathrm{M}$, et al. Characterising phosphorus and nitrate inputs to a rural river using high-frequency concentration-flow relationships[J]. Science of the Total Environment. 2015， 511:608-20.

7. Johnes PJ. Uncertainties in annual riverine phosphorus load estimation: Impact of load estimation methodology, sampling frequency, baseflow index and catchment population density[J]. Journal of Hydrology. 2007， 332(1-2):241-58.

8. O'Brien KR, Weber TR, Leigh C, Burford MA. Sediment and nutrient budgets are inherently dynamic: evidence from a long-term study of two subtropical reservoirs[J]. Hydrology \& Earth System Sciences. 2016, 20(12):4881-94.

9. Viviano G, Salerno F, Manfredi EC, Polesello S, Valsecchi S, Tartari G. Surrogate measures for providing high frequency estimates of total phosphorus concentrations in urban watersheds[J]. 
Water Research. 2014, 64(7):265-77.

10. Feng Y, Zhen H, Liu C. Analysis of pollution characteristics of storm runoff in the upper reaches of Dahuofang Reservoir[J]. Environmental Protection and Circular Economy. 2011，31(6):46-8.

11. Zhou J, Zhang M, Li Z. Dams altered Yangtze River phosphorus and restoration countermeasures[J]. Journal of Lake Sciences 2018，30(4).

12. Mahowald N, Jickells TD, Baker AR, Artaxo P, Benitez-Nelson CR, Bergametti G, et al. Global distribution of atmospheric phosphorus sources, concentrations and deposition rates, and anthropogenic impacts[J]. Global Biogeochemical Cycles. 2008，22(4):37-42.

13. Du E, De Vries W, Han W, Liu X, Yan Z, Jiang Y. Imbalanced phosphorus and nitrogen deposition in China's forests[J]. Atmospheric Chemistry \& Physics. 2016, 16(13):8571-9.

14. Mao Z, Yang S, Wang L, Cheng D. Areview of phosphorus retention in river ecosystems[J]. Journal of Hydraulic Engineering 2015，46(5):515-24.

15. Wang X. Monitoring and analysis of water quality in and out of Dahuofang reservoir[J]. Heilongjiang Science and Technology of Water Conservancy. 2012, 40(3):59-60.

16. Xu S. FORTRAN Common Algorithm Assembly:
TSINGHUA UNIVERSITY PRESS; 1992.

17. Zheng B, Qin Y, Zhang L, Ma Y, Zhao Y, Wen Q. Sixty-year sedimentary records of polymetallic contamination $(\mathrm{Cu}, \mathrm{Zn}, \mathrm{Cd}, \mathrm{Pb}, \mathrm{As})$ in the Dahuofang Reservoir in Northeast China[J]. Environmental Earth Sciences. 2016, 75(6):486.

18. Wang L, Zhang L. Study on Ecolodical Changes of Hydrobilogy in Dahuofang Reservoir Liao Ning[J]. Hailongjiang Environmental Journal 2002 , 26(4):119-22.

19. Guo R, He X. Spatial variations and ecological risk assessment of heavy metals in surface sediments on the upper reaches of Hun River, Northeast China[J]. Environmental Earth Sciences. 2013， 70(3):1083-90.

20. Lin C, Wang Z, He M, Li Y, Liu R, Yang Z. Phosphorus sorption and fraction characteristics in the upper, middle and low reach sediments of the Daliao river systems, China[J]. Journal of Hazardous Materials. 2009, 170(1):278.

21. Zhang M, Xu Y, Shao M, Cai Q. Spatiotemporal distribution of total nitrogen and total phosphorus in sediments of XiangXiBay, Three Gorges Reservoir[J]. Chinese Journal of Applied Ecology. 2009 , 20(11):2799-805.

22. Gao Yn, Zhou D, Yu P, Liang G, Bai F, Fu J. Secondary flocculation ultrafiltration treatment for Dahuofang reservoir high turbidity pollution [J]. Technology of Water Treatment. 2014(10):116-9. 